\title{
A BNCC e o livro didático de inglês: (im)possibilidades de ensino ativo
}

\section{BNCC and the English teaching book: (im)possibilities of active learning}

\author{
Elaine de Oliveira Pereira ${ }^{1}$ \\ Mara Lúcia Castilho²
}

\begin{abstract}
Resumo
Este trabalho tem como objetivo analisar como o livro Manual do Professor Time to Share contribui para o aprendizado ativo da língua inglesa, na perspectiva do ensino híbrido, mediante as novas concepções de ensino e aprendizagem da BNCC. Para tal, foi realizada uma reflexão sobre o texto da BNCC para o ensino fundamental, anos finais, a fim de identificar atividades no livro didático que possibilitem o uso de metodologias ativas e personalizadas de ensino e que contribuem para a aprendizagem da língua inglesa; e conhecer se o livro está em consonância com a proposta da BNCC para a perspectiva de ensino híbrido. Os resultados evidenciaram que não está em total acordo com as orientações da BNCC e proporciona poucos momentos de aprendizagem ativa da língua alvo.
\end{abstract}

Palavras-chave: BNCC. Ensino-aprendizagem de Inglês. Metodologias ativas de ensino.

\begin{abstract}
This study aims to analyze how the textbook of the teacher Time to Share contributes to the active learning of the English Language, in the perspective of hybrid teaching, through the new conceptions of teaching and learning of BNCC. To this end, a reflection was made on the text of the BNCC for elementary education, final years, in order to identify activities in the textbook that enable the use of active and personalized teaching methodologies and that contribute to the learning of the English language; and to know if the textbook is in consonance with the BNCC proposal for the hybrid teaching perspective. The results showed that it is not in full agreement with the guidelines of the BNCC and provides few moments for active learning the target language.
\end{abstract}

Keywords: BNCC. English teaching-learning. Active learning.

\section{Introdução}

A vida é uma narrativa dinâmica com enredo contínuo, construída com fragmentos de múltiplas histórias que vivenciamos e compartilhamos com pessoas tanto próximas fisicamente como virtualmente. $\mathrm{Na}$ vida, aprendemos mais e melhor quando há significado para aquilo que estamos vivenciando. Construir histórias que façam sentido nos ajuda a compreender melhor o mundo em que vivemos, os outros e a nós mesmos (MORAN, 2015). Assim, é possível educar pessoas e estas conseguirem se comunicar, fazer escolhas, ser produtivas e realizadas como ser único e social.

Segundo Camargo e Daros (2018), o mundo está cada vez mais conectado, as instituições e a sociedade estão cada vez mais (inter)relacionadas. Por isso, são necessárias mudanças nos métodos

\footnotetext{
1 Graduada em Letras - Licenciatura Inglês. Instituto Federal de Educação, Ciência e Tecnologia de Brasília, Brasília, DF, Brasil. Orcid: https://orcid.org/0000-0002-3338-7737 E-mail: elaineoliveeira@gmail.com

2 Doutora em Linguística. Instituto Federal de Educação, Ciência e Tecnologia de Brasília, Brasília, DF, Brasil. Orcid: https://orcid.org/0000-0002-8467-447X E-mail: maralucia.castilho@gmail.com
} 
de ensino-aprendizagem para termos escolas pluralistas e capazes de acompanhar as demandas do século XXI. Nesse contexto, as metodologias ativas de ensino e aprendizagem são aliadas fundamentais desse processo, pois colocam o estudante como protagonista da sua aprendizagem, oportunizando 0 desenvolvimento crítico, criativo, autônomo, significativo, ativo, emocional e cognitivo. Sobre esse tema, para a Base Nacional Comum Curricular (BNCC), as escolas devem promover práticas pedagógicas diferenciadas que atendam às necessidades dos estudantes.

Em face dessa necessidade do ensino e da aprendizagem ativos da língua inglesa, a escolha dos livros didáticos como ferramenta complementar a esse processo é de grande importância para despertar a autonomia e a consciência crítica dos estudantes. Sabe-se, no entanto, que, para esse despertar, o estudante precisa do auxílio do professor, alguém capaz de buscar possibilidades e, assim, contribuir para o amadurecimento dessa autonomia e dessa consciência. Posto isso, a finalidade desta pesquisa foi analisar se a proposta da BNCC está contemplada em um livro didático, aprovado pelo PNLD 2020, adotado por uma escola da rede pública do DF e se este está de acordo com a perspectiva do ensino híbrido, proposta atual para o ensino. Para tanto, pretendeu-se responder às seguintes questões: se as atividades do livro, objeto deste estudo, possibilitam o uso de metodologias ativas de ensino e se contribuem para a aprendizagem da língua inglesa; e se o livro didático atende à proposta da BNCC na perspectiva de ensino híbrido. Este estudo justifica-se por buscar conhecer se os livros aprovados pelo PNLD contribuem para o aprendizado ativo da língua inglesa na perspectiva de ensino híbrido de estudantes do $6^{\circ}$ ano.

Em um primeiro momento, será apresentada a revisão da literatura sobre a importância das metodologias ativas de ensino para a aprendizagem ativa da língua inglesa, e sobre as propostas da BNCC para o ensino fundamental. Em um segundo momento, será relatada a metodologia utilizada na pesquisa. E, por fim, serão apresentados os resultados da análise documental do livro Manual do Professor intitulado Time to Share.

\section{A Base Nacional Comum Curricular (BNCC)}

A Base Nacional Comum Curricular (BNCC) é um documento de carácter normativo que estabelece um conjunto de regras dos conhecimentos essenciais que os estudantes devem desenvolver ao longo de todas as etapas da educação básica. Seu principal objetivo é ser norteador da qualidade da educação no País ao estabelecer a base das áreas do conhecimento desde o ensino infantil até o médio (BRASIL, 2018). 
Esse documento não propõe um currículo mínimo, mas parece propor um conjunto de referenciais para a construção deste. No entanto, para Tílio (2019, p. 12), a BNCC "é, na prática, currículo mínimo, sim, pois tudo que consta nela é obrigatório e não pode deixar de ser incluído no currículo". Esse entendimento se dá em razão de, no caso da língua inglesa, a BNCC determinar também os conteúdos gramaticais a serem ensinados e o que os estudantes devem aprender em cada ano.

O ensino fundamental, com nove anos de duração, é a etapa mais longa da educação básica, e tem início aos seis anos de idade. Para os anos finais dessa etapa do ensino, a Base reconhece que os adolescentes devem ser compreendidos como sujeitos em desenvolvimento, com identidade, formação social e cultural próprios. Portanto, as escolas devem promover práticas pedagógicas diferenciadas para atender às necessidades desses estudantes. Devem, ainda, proporcionar abordagens mais integrais e plurais que reconheçam suas identidades.

Para tanto, ao longo da educação básica, as escolas devem viabilizar aos estudantes 0 desenvolvimento das 10 competências gerais definidas na BNCC, sendo uma delas definida como "a mobilização de conhecimentos, habilidades, atitudes e valores para resolver demandas complexas da vida cotidiana, do pleno exercício da cidadania e do mundo do trabalho" (BRASIL, 2018, p. 14). A BNCC também define um conjunto de habilidades e objetos de conhecimento organizados por unidades temáticas.

Assim, as competências da área de linguagens para o ensino fundamental - anos finais têm como finalidade possibilitar aos estudantes compreender, reconhecer, respeitar, utilizar e interagir por intermédio de diferentes linguagens e se posicionar criticamente sobre elas. A BNCC declara que as linguagens são uma "construção humana, histórica, social e cultural, de natureza dinâmica" (BRASIL, 2018, p. 65). Nesse sentido, a língua inglesa é reconhecida pela BNCC como língua franca, ou seja, como língua de comunicação global e plural. $O$ inglês é utilizado por falantes em todo o mundo, que possuem repertórios linguísticos e culturais próprios. Para a BNCC, o ensino da língua inglesa não deve servir apenas como ferramenta de acesso a culturas de países hegemônicos, e sim possibilitar o acesso aos saberes linguísticos para engajamento e participação, contribuir para o desenvolvimento do pensamento crítico dos estudantes, para o exercício da cidadania ativa e ampliação das possibilidades de interação e mobilidade, promover novas possibilidades para o percurso formativo e de continuidade dos estudos (BRASIL, 2018).

Canagarajah (2005) afirma que o caráter de língua franca conferido à língua inglesa pode favorecer a manifestação de identidade e culturas locais. De acordo com Rajagopalan (2009), o inglês como língua franca não tem status privilegiado, ele pertence a todos que o utilizam independente do modo ou da forma como o usam.

LínguaTec, Instituto Federal de Educação, Ciência e Tecnologia do Rio Grande do Sul, Bento Gonçalves 
Para o desenvolvimento do ensino e aprendizagem da língua inglesa, a BNCC define 5 eixos organizadores, apresentados na Figura 1. Por meio desses eixos, os estudantes devem ser capazes de fazer uso de diferentes linguagens para se inserir em um mundo globalizado, plurilíngue e multicultural, reconhecer, valorizar e respeitar as diversidades e usos diversos e multimodais da língua. Dessa forma, podemos entender que a BNCC não espera que as práticas pedagógicas sejam construídas para que os estudantes alcancem níveis específicos de proficiência na língua inglesa em cada etapa do percurso formativo, não contribuindo, assim, para o mito do falante nativo. Para cada um dos eixos e para cada etapa do ensino fundamental são definidas unidades temáticas, objetos do conhecimento e habilidades a serem desenvolvidas. Para cada unidade, um objeto de conhecimento é escolhido e um conjunto de habilidades relacionadas a ele é detalhado (BRASIL, 2018).

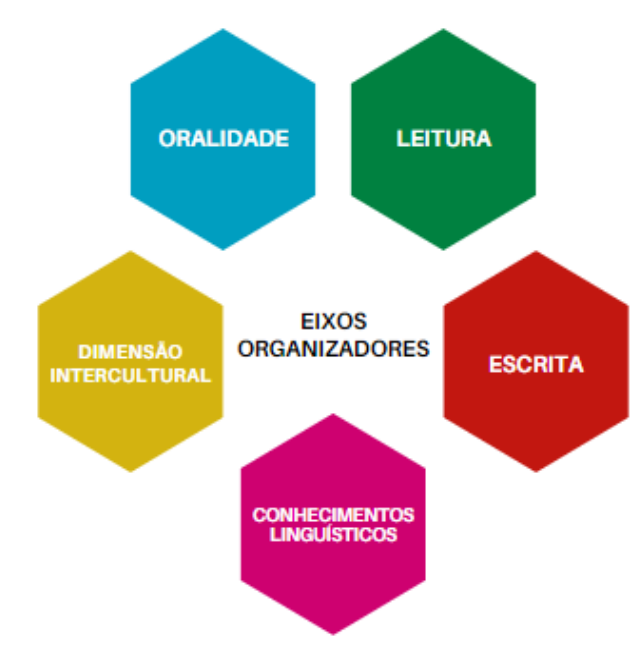

Figura 1. Eixos organizadores da língua inglesa. Fonte: Elaborada pela autora a partir da BNCC (BRASIL, 2018).

O eixo Dimensão Intercultural pode ser considerado como eixo inovador da proposta. Para a BNCC, as culturas estão em constante "processo de interação e (re)construção" (BRASIL, 2018, p. 245); assim, pessoas com repertórios linguísticos e culturais diversos vivenciam a construção de identidades plurais. Nesse sentido, a BNCC reafirma sua visão do inglês como língua franca, impondo desafios e novas prioridades para o ensino, como as reflexões sobre as relações entre língua, identidade e cultura, e o desenvolvimento da competência intercultural.

O ensino ativo, fundamentado nessa proposta da BNCC, será apresentado a seguir de modo a possibilitar melhor compreensão do tema.

\section{Metodologias ativas de aprendizagem no ensino híbrido}


O modelo exclusivo de educação tradicional vem sendo questionado e criticado nos últimos anos por alunos e professores. Os estudantes do ensino básico e superior reclamam do ensino essencialmente transmissivo, focado no conteúdo, sem relação com o seu dia a dia. Já os professores reclamam da falta de interesse e de envolvimento dos alunos e das condições do trabalho docente (CAMARGO; DAROS, 2018). Segundo Lévy (1999), a função principal do ensino já não pode ser transmitir conhecimentos, mas criar desafios para o processo de aprender e pensar.

Com 0 advento das novas tecnologias e do acesso à informação, as dinâmicas sociais se transformaram rapidamente e, com essas mudanças, o modelo de educação tradicional parece não ser mais efetivo. Mesmo diante de tantos avanços tecnológicos e científicos, o modelo de aula expositiva e os recursos utilizados continuam a predominar nas salas de aulas. Trocou-se quadro e giz por recursos audiovisuais; no entanto, os estudantes continuam a ser passivos no processo de ensino e aprendizagem (CAMARGO; DAROS, 2018).

As metodologias ativas de aprendizagem colocam o estudante no centro da sua aprendizagem, ou seja, o estudante deixa de ser espectador e passa a ser o responsável pela sua aprendizagem. Ao utilizar metodologias ativas, o professor passa a ser 0 mediador, o organizador das atividades pedagógicas (CAMARGO; DAROS, 2018). Atualmente, com o avanço das tecnologias e do acesso à informação, a escola necessita ser redesenhada e os professores precisam acompanhar essa mudança. O ensino e a aprendizagem podem acontecer de várias formas, em espaços diferentes e em todos os momentos. Segundo Moran (2015, p. 27), "tudo pode ser misturado, combinado, e podemos, com os mesmos ingredientes, preparar diversos "pratos", com sabores muito diferentes."

De acordo com Camargo e Daros (2018), criar condições para a participação ativa dos alunos implica a mudança da práxis pedagógica e no desenvolvimento de estratégias que garantam o aprendizado. "A inovação é uma das formas de transformar a educação" (CAMARGO; DAROS, 2018, p. 4), e, por isso, inovar na educação é essencialmente necessário.

É, nesse sentido, que o modelo de ensino híbrido se apresenta como abordagem pedagógica, combinando atividades presenciais e atividades por meio das Tecnologias da Informação e Comunicação (TICs). Para Bacich, Neto e Trevisani (2015), não é necessário que o professor abandone o que já sabe para promover o uso das TICs na educação, e sim uma integração criativa e crítica dos "dois mundos" — virtual e presencial. Nessa abordagem, o professor passa a ter função de mediador na sala de aula, e a responsabilidade pela aprendizagem passa a ser do estudante, ao assumir uma postura mais autônoma, participativa, resolvendo problemas, desenvolvendo projetos, criando percursos para o desenvolvimento crítico individual e coletivo. 
Para o ensino híbrido, o professor é essencial na organização e no desenvolvimento das estratégias de ensino-aprendizagem. Para que as atividades planejadas possam atender às demandas da sala de aula, o professor precisa identificá-las e orientar o seu trabalho pedagógico para que a construção do conhecimento pelos estudantes ocorra de forma autônoma e colaborativa, conforme Figura 2. Essa autonomia, característica do ensino híbrido, segundo Schneider (2015), pode ser desenvolvida gradualmente por meio das tecnologias, pois essas, estando à disposição dos estudantes, proporcionam uma diversidade de ferramentas que promovem o aprimoramento do processo de aprendizagem. Outra característica do ensino híbrido é o trabalho com foco no compartilhamento de experiências e na construção do conhecimento a partir do trabalho coletivo, pois o trabalho em grupo possibilita aos estudantes vivenciar diversos pontos de vista e realidades distintas. $E$, segundo Bacich, Neto e Trevisani (2015), essas atividades coletivas podem ser mediadas pelas tecnologias ou durante discussões em sala de aula.

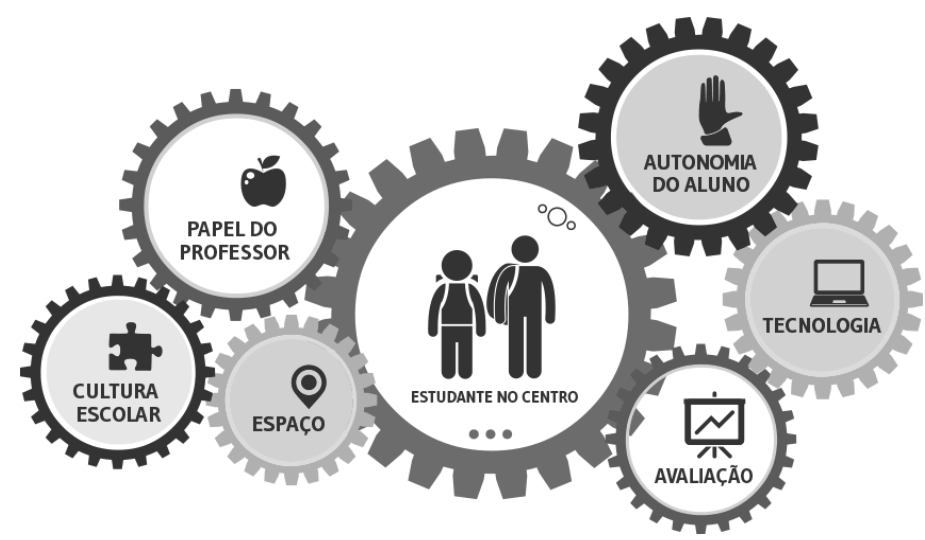

Figura 2. Organização do Ensino Híbrido.

Fonte: Porvir (2020 apud, p. 63, BACICH, NETO, TREVISANI, 2015).

Sendo assim, cabe ao professor decidir como utilizará as TICs, enquanto recursos pedagógicos e tecnológicos à sua disposição, para fazer essa ponte entre as práticas pedagógicas e as necessidades dos estudantes na sala de aula.

É nesse contexto que as atividades propostas pelos materiais didáticos, segundo Ludwig e Machado (2017), são relevantes, pois auxiliam o processo de ensino e aprendizagem da língua inglesa, e também proporcionam ao professor segurança para ensinar e a autonomia dos estudantes.

\section{Programa Nacional do Livro e do Material Didático (PNLD)}


O Programa Nacional do Livro e do Material Didático (PNLD) tem como proposta avaliar e disponibilizar obras didáticas, pedagógicas e literárias, de forma sistemática, regular e gratuita, às escolas e instituições públicas de educação básica do Brasil. 0 governo federal possui três planos de distribuição desses materiais: o PNLD (para o ensino fundamental), o PNLEM (Programa Nacional do Livro Didático para o Ensino Médio) e o PNLA (Programa Nacional do Livro Didático para a Alfabetização de Jovens e Adultos) (BRASIL, 2020).

Para a execução do PNLD, são realizadas as inscrições dos livros didáticos no site do FNDE (Fundo Nacional de Desenvolvimento da Educação). Em seguida, os livros são analisados pelo IPT (Tecnológicas do Estado de São Paulo) para assegurar que as obras inscritas se enquadrem nas normas do edital. Depois, são encaminhados à SEB (Secretaria de Educação Básica), que escolhe especialistas responsáveis pela avaliação pedagógica e produção de resenhas que compõem o guia de livros didáticos. Esses guias são enviados às escolas e ficam disponíveis no site do FNDE (BRASIL, 2020).

Depois disso, professores e diretores analisam e escolhem o livro a ser adotado pela escola. Os livros podem ser utilizados por três anos consecutivos, exceto as obras destinadas aos anos finais do ensino fundamental, que passam a ter ciclos de quatro anos. As obras didáticas destinadas aos anos finais do ensino fundamental são de três tipos: Disciplinares, Interdisciplinares e Projetos Integradores, em conformidade com a BNCC (BRASIL, 2018). Nesta pesquisa, o livro Manual do Professor intitulado Time to Share, objeto deste estudo, compõe a lista de obras aprovadas pelo PNLD 2020 e foi selecionado por uma escola da Secretaria de Educação do Distrito Federal (SEDF) seguindo as recomendações do FNDE.

\section{Percurso Metodológico}

Esta pesquisa foi de caráter exploratório-descritivo em razão de seu objetivo ter sido analisar e identificar elementos do ensino híbrido presentes na BNCC e no livro didático. Segundo Marconi e Lakatos (2003), esse tipo de pesquisa permite a obtenção de descrições tanto quantitativas quanto qualitativas por meio de procedimentos sistemáticos para a análise de dados. Trata-se de abordagem qualitativa de pesquisa em razão de buscar descrever o objeto estudado, no caso o livro Manual do Professor Time to Share, para verificar se, de alguma maneira, ele contempla o proposto na BNCC no que se refere ao ensino híbrido. A análise dos textos não seguiu nenhuma proposta metodológica específica, apenas cotejou a relação existente entre o proposto na atividade do livro didático, o sugerido pela BNCC e o referencial teórico utilizado nesta pesquisa, no que se refere ao uso de metodologias ativas, mais especificamente para o ensino híbrido. 
O livro analisado foi selecionado por ter sido aprovado pelo PNLD 2020 e reformulado para atender às propostas da BNCC. 0 acesso desta pesquisadora a ele foi online ${ }^{3}$, antes do início da pandemia do coronavírus, em 2020 e, portanto, foi o disponível para análise, sendo esta realizada ao longo dos meses de novembro e dezembro daquele mesmo ano.

\section{Análise dos Dados Encontrados}

A coleção Time to Share, objeto deste estudo, de autoria de Alice Ribeiro Silvestre, foi publicada pela Editora Saraiva, em 2020. Ela é composta por quatro volumes, dirigidos à faixa etária de 11 a 14 anos. A coleção inclui o Livro do Estudante, o Manual do Professor e o CD de áudio complementar.

O livro selecionado para análise foi o Manual do Professor do primeiro ano da segunda etapa do ensino fundamental, isto é, sexto ano. Esse livro é composto por uma unidade de abertura e oito unidades regulares, além de seções de revisão, de autoavaliação, de vocabulário e um caderno de atividades. As atividades de cada unidade, segundo o título das seções, buscam contemplar as quatro habilidades do ensino de língua inglesa (reading, listening, speaking e writing). Para análise, nesta pesquisa, foram selecionadas as três primeiras unidades do livro por apresentarem uma breve orientação para o início do ensino e aprendizagem de um novo idioma. Além disso, buscou-se verificar se, logo nas primeiras unidades para o ensino de uma língua adicional, a proposta da BNCC foi considerada.

O material, inicialmente, apresenta orientações gerais para os professores, as quais elencam alguns pressupostos teórico-metodológicos, como auxílio ao professor para suas práticas didáticopedagógicas, levando em consideração as diversas mudanças ocorridas no componente curricular a partir da BNCC. Assim, nessas orientações são apresentados um breve resumo do documento norteador da educação brasileira, a BNCC, e também as competências e habilidades da língua inglesa que os estudantes devem desenvolver ao longo do ano.

Neste trabalho, as análises contemplaram apenas as habilidades reading e speaking de cada uma das três unidades selecionadas para o estudo, pois elas possuem o mesmo tema dentro das seções e subseções que as compõem. As demais habilidades - writing e listening — dessas mesmas unidades não contemplavam o mesmo tema e, portanto, pareceram desconectadas das demais. A seguir, serão apresentadas as análises das atividades propostas para as habilidades foco deste estudo, por unidade, fundamentada no ensino ativo da língua inglesa proposto pela BNCC.

\footnotetext{
${ }^{3}$ https://api.plurall.net/media_viewer/documents/2597803.
} 
A Unidade 01 desse livro didático é intitulada English in the World, tendo como temática principal a vida familiar e social, e diversidade cultural. Antes de realizar a primeira atividade de escuta, é solicitado, em português, ao estudante que responda a quatro perguntas sobre a forma como eles cumprimentam pessoas no dia a dia, quais as situações de uso da linguagem formal e informal para esse procedimento, se os estudantes conhecem os personagens dos desenhos animados apresentados na seção e se os diálogos usados por esses personagens são formais ou informais. Também é apresentado um quadro com informações, em português, sobre linguagem formal e informal. Essa preparação parece não estar de acordo com a preparação indicada para se trabalhar de forma ativa, pois, de acordo com Camargo e Daros (2018), o ensino ativo coloca o estudante no centro do aprendizado, ou seja, o estudante se torna responsável pelo seu percurso formativo. Nesse sentido, as atividades devem promover maior interação entre o grupo, o trabalho colaborativo, aguçar a curiosidade, a criatividade e instigar a pesquisa. As perguntas encontradas nessa atividade do livro parecem não dialogar com as realidades dos estudantes, pois inicia com cumprimentos a pessoas e, em seguida, solicita-se que escutem um áudio com personagens de desenho animado. Além disso, é possível que nem todos os estudantes conheçam esses personagens e que também não façam uso dos cumprimentos propostos no livro em seu dia a dia.

Para a realização da atividade de speaking dessa mesma Unidade 01, solicita-se ao estudante, em português, que observe cinco imagens e que digam, também em português, o que as pessoas dos textos estão fazendo, se eles cumprimentam pessoas mais jovens e mais velhas da mesma maneira, e pergunta quais expressões elas usariam, em inglês, nessas situações distintas. Em seguida, os estudantes devem escrever em seus cadernos as expressões em inglês apresentadas que podem ser usadas para saudações. Depois, é solicitada a leitura de um texto em português para os estudantes fazerem uma reflexão, em grupos, sobre o tema trabalhado. Percebe-se que, nessa atividade, com a adaptação do professor, seria possível torná-la ativa, pois há situação de trabalho colaborativo característica do ensino híbrido - com possibilidade de maior interação entre os estudantes e de pesquisa prévia sobre as saudações possíveis de serem utilizadas para que, assim, dialogue com a realidade dos estudantes. No entanto, não foi observada consonância com a BNCC, pois a língua inglesa ainda é trabalhada de forma descontextualizada e instrumentalizada. Para a BNCC, as práticas de linguagem oral dos estudantes e suas identidades particulares ao falar a língua devem ser consideradas, não tendo sido observada essa prática. Outro ponto identificado foi o uso da língua materna em todos os comandos das atividades em vez de ser utilizada a língua alvo.

Para melhor compreensão dos dados encontrados na análise da Unidade 01 do livro, o Quadro 1 apresenta um breve resumo com a habilidade a ser trabalhada nas seções analisadas, a orientação da 
atividade a ser desenvolvida, o número da seção do livro e a análise sobre haver ou não relação com o ensino híbrido e com a proposta da BNCC.

\begin{tabular}{|c|c|c|l|l|}
\hline \multicolumn{5}{|c|}{ Unidade 01 - English in the World } \\
\hline Habilidade & Atividade & Seção & \multicolumn{1}{|c|}{ Relação com o ensino híbrido } & Atende às propostas da BNCC \\
\hline Listening & Before Listening & 24 & $\begin{array}{l}\text { Não, pois as atividades são } \\
\text { descontextualizadas e não colocam o } \\
\text { estudante como centro do } \\
\text { aprendizado. }\end{array}$ & $\begin{array}{l}\text { Não, pois não parece promover um } \\
\text { ensino focado nas demandas dos } \\
\text { estudantes. }\end{array}$ \\
\hline Speaking & Speaking & 26 & $\begin{array}{l}\text { É possível, se houver adaptação } \\
\text { prévia das atividades por parte do } \\
\text { professor. }\end{array}$ & $\begin{array}{l}\text { Não, pois a língua não é trabalhada } \\
\text { de forma a contemplar a realidade } \\
\text { dos estudantes. }\end{array}$ \\
\hline
\end{tabular}

Quadro 1. English in the world.

Fonte: Elaborada pela autora a partir da análise do livro didático objeto deste estudo.

A Unidade 02 é intitulada Citizenship for All e os temas principais abordados são diversidade cultural, educação em direitos humanos, e vida familiar e social. Como introdução à atividade de listening, nesta unidade, pede-se ao estudante, em português, que responda a 4 questões sobre o texto, em inglês, trabalhado anteriormente. Na primeira pergunta, solicita-se ao estudante que fale se conhece ou se já ouviu falar de pessoas que mudaram para o Brasil em busca de uma vida melhor. Em seguida, que dificuldades essas pessoas enfrentam ao não ter documentação, como os filhos dessas pessoas são afetados e os solicita, ainda, para observar duas imagens e dizer o que as pessoas estão fazendo. 0 tema abordado nesta atividade é muito importante para que os estudantes discutam e reflitam sobre as relações da sociedade com os imigrantes. O texto utilizado como base para esta atividade tem vocabulário rico e de simples compreensão, porém as perguntas norteadoras para a discussão, mais uma vez, estão em língua portuguesa. De acordo com a BNCC, as práticas de produção oral em língua inglesa proporcionam o desenvolvimento de comportamentos e atitudes, como lidar com inseguranças, ter voz e dar oportunidade ao outro e superar mal-entendidos. Nesse sentido, essa preparação não parece estar de acordo com as diretrizes discutidas pela BNCC, pois toda a atividade é planejada em língua materna, excluindo, dessa forma, a oportunidade de prática da língua alvo pelos estudantes.

Para a realização da atividade de speaking, dessa mesma Unidade, solicita-se ao estudante a leitura de três textos, em inglês, sobre jovens ativistas e, em seguida, pede-se para completarem um quadro com as informações pessoais dos mesmos. Por último, solicita-se que os estudantes, em pares, escolham um dos ativistas e o apresente, em inglês, para a sala usando como exemplo a estrutura de três sentenças sugeridas no livro. A forma como a língua inglesa é trabalhada nesta atividade dialoga 
com os objetos de conhecimento propostos pela BNCC. Nesse sentido, os estudantes devem compreender textos orais de cunho descritivo ou narrativo e produzir textos orais com mediação do professor (BRASIL, 2018, p. 253). No entanto, percebemos que, nesta atividade, o reading e o writing têm maior destaque mesmo sendo uma proposta voltada para o aprimoramento do speaking, apesar de a BNCC esclarecer que as quatro habilidades da língua inglesa não devem ser trabalhadas de forma independente. Outro ponto identificado é que há poucos momentos de interações entre os estudantes para o compartilhamento de conhecimentos prévios e de produção oral espontânea. Sendo assim, esta atividade não está em consonância com a proposta de ensino híbrido, em que, segundo Bacich, Neto e Trevisani (2019), o professor deve planejar suas aulas de modo a contemplar as demandas dos estudantes, por meio de atividades que promovam a autonomia e a colaboração entre eles. Dessa forma, o percurso formativo é construído a partir dessas interações coletivas e do compartilhamento das vivências do grupo e as habilidades reading e writing, geralmente, são realizadas individualmente.

Para melhor compreensão dos dados encontrados na análise da Unidade 02 do livro, o Quadro 2 apresenta um breve resumo com a habilidade a ser trabalhada nas seções analisadas, a orientação da atividade a ser desenvolvida, o número da seção do livro e a análise sobre haver ou não relação com o ensino híbrido e com a proposta da BNCC.

\begin{tabular}{|c|c|c|c|c|}
\hline \multicolumn{5}{|c|}{ Unidade 02 - Citizenship for All } \\
\hline Habilidade & Atividade & Seção & Relação com o ensino híbrido & Atende às propostas da BNCC \\
\hline Sistening & Before Listening & 42 & $\begin{array}{l}\text { Não, pois as atividades parecem não } \\
\text { contribuir para o desenvolvimento da } \\
\text { autonomia e do trabalho coletivo entre } \\
\text { os estudantes. }\end{array}$ & $\begin{array}{l}\text { Não, pois o planejamento da } \\
\text { atividade não oferece oportunidade } \\
\text { de prática da língua alvo pelos } \\
\text { estudantes. }\end{array}$ \\
\hline & Speaking & 44 & $\begin{array}{l}\text { Não, pois a produção oral não é ét } \\
\text { espontânea, os estudantes devem } \\
\text { apenas reproduzir sentenças prontas. }\end{array}$ & $\begin{array}{l}\text { Parcialmente, pois apesar dos } \\
\text { textos base e das perguntas serem } \\
\text { em inglês, a produção oral é pouco } \\
\text { contemplada. }\end{array}$ \\
\hline
\end{tabular}

Quadro 2. Citizenship for all.

Fonte: Elaborada pela autora a partir da análise do livro didático objeto deste estudo.

A Unidade 03 analisada tem como título Family Pictures e os temas principais abordados são vida familiar e social, educação em direitos humanos e diversidade cultural. Antes de realizar a atividade de listening proposta, solicita-se, em português, ao estudante que observe fotos de algumas famílias e as relacionem com palavras em inglês, dispostas logo abaixo dessas imagens. Depois, solicita-se, em português, aos estudantes que respondam como eles definem uma família. Em seguida, os estudantes devem ouvir um áudio e responder, em português, a três perguntas, e combinar palavras em inglês com 
as imagens apresentadas. Dando sequência a esta atividade, solicita-se, em inglês, que os estudantes ouçam o áudio novamente e escrevam no caderno quais das sentenças apresentadas são verdadeiras. No início desta atividade, identifica-se que a proposta pode ser adaptada pelo professor para que 0 contexto seja o mais próximo possível da realidade dos estudantes. O professor pode requisitar ao estudante 0 estudo prévio do vocabulário, que discuta e se informe com seus familiares como suas famílias são formadas e, ainda, que compartilhe em sala suas experiências com os demais colegas. Dessa forma, o professor poderá ter mais tempo para trabalhar o desenvolvimento de escuta dos estudantes em sala de aula, de criticidade e da autonomia destes. Segundo Bacich, Neto e Trevisani (2019), em um ambiente ativo de aprendizagem, o estudante se envolve e constrói sua melhor forma de aprender junto ao professor e colegas. Dessa maneira, se houver essas adaptações, o professor conseguirá adequar-se às metodologias ativas e, por consequência, ao modelo de ensino híbrido.

A atividade de speaking da Unidade 03 solicita ao estudante a criação de uma árvore genealógica e, em seguida, a apresentação desta à turma. Essa árvore deve ser desenhada tendo como base a família do estudante ou os exemplos apresentados no livro, utilizando o vocabulário mostrado em um quadro específico para esta atividade. Em seguida, os estudantes devem ler e refletir sobre a frase "O amor da família e a admiração dos amigos é muito mais importante do que a riqueza e os privilégios." Essa atividade está de acordo com as orientações da BNCC, pois nas competências gerais da educação básica, espera-se que o estudante utilize diferentes linguagens (verbal, visual, sonora, corporal e digital) para o seu desenvolvimento individual e social. No entanto, também foi possível identificar que os momentos planejados para o aprimoramento da fala, mais uma vez, ficam comprometidos, pois as atividades dessa unidade priorizam as habilidades de reading e writing em detrimento do speaking. Uma proposta interessante observada foi planejamento de atividade lúdica, que segundo Mattar (2017), é um exercício da aprendizagem ativa, pois, o envolvimento dos estudantes é intenso, eles planejam e executam seus objetivos da forma como desejam. Ainda para o autor, as atividades lúdicas são baseadas nas experiências de vida dos estudantes, proporcionando aos mesmos o interesse, a criatividade e 0 trabalho em grupo e individual. Outra questão é a sugestão do uso de vocabulário limitado ao apresentado no quadro. Se o professor propuser ao estudante a busca por vocabulário diverso ao sugerido, para falarem sobre a árvore genealógica de sua família, é possível desenvolver ainda mais a autonomia do estudante, característica do ensino híbrido.

Para melhor compreensão dos dados encontrados na análise da Unidade 03 do livro, o Quadro 3 apresenta um breve resumo com a habilidade a ser trabalhada nas seções analisadas, a orientação da atividade a ser desenvolvida, o número da seção do livro e a análise sobre haver ou não relação com o ensino híbrido e com a proposta da BNCC.

LínguaTec, Instituto Federal de Educação, Ciência e Tecnologia do Rio Grande do Sul, Bento Gonçalves 


\begin{tabular}{|c|c|c|l|l|}
\hline \multicolumn{5}{|c|}{ Unidade 03 - Family Pictures } \\
\hline Habilidade & Atividade & Seção & \multicolumn{1}{|c|}{ Relação com o ensino híbrido } & Atende às propostas da BNCC \\
\hline Listening & Before Listening & 60 & $\begin{array}{l}\text { É possível, se houver adaptação } \\
\text { prévia da atividade por parte do } \\
\text { professor. }\end{array}$ & $\begin{array}{l}\text { Em parte, pois a prática da escuta em } \\
\text { língua inglesa parece ser uma } \\
\text { habilidade pouco explorada pelo livro. }\end{array}$ \\
\hline & Speaking & 62 & $\begin{array}{l}\text { Sim, pois a atividade promove um } \\
\text { momento de interação lúdica na sala } \\
\text { de aula. }\end{array}$ & $\begin{array}{l}\text { Em parte, atividades diferenciadas } \\
\text { são propostas, no entanto a fala não } \\
\text { parece ter a mesma relevância que as } \\
\text { habilidades de escrita e leitura. }\end{array}$ \\
\hline
\end{tabular}

Quadro 3. Family pictures.

Fonte: Elaborada pela autora a partir da análise do livro didático objeto deste estudo.

A partir desses resultados observou-se que, apesar de a BNCC orientar o ensino e a aprendizagem da língua de inglesa de modo não compartimentalizado, não instrumentalizado, que atenda às demandas dos estudantes, e que trabalhe as habilidades de modo inter-relacionadas, 0 Manual do Professor Time to Share parece priorizar as habilidades de leitura e escrita, habilidades estas ainda muito cobradas nos exames nacionais. O ensino híbrido, fundamentado em metodologias ativas, dependerá do conhecimento e da habilidade do professor para realizá-lo.

É importante mencionar que os livros aprovados pelo PNLD de 2020 foram reformulados para atender as novas orientações da BNCC e, no entanto, as unidades analisadas neste estudo parecem ainda seguir o mesmo modelo de atividades de livros anteriores, apresentando atividades que não representam a realidade dos estudantes, isto é, por vezes mecânicas e descontextualizadas.

\section{Considerações Finais}

Este trabalho objetivou analisar como as atividades do livro Manual do Professor Time to Share contribuem para o aprendizado ativo da língua inglesa, na perspectiva do ensino híbrido, mediante as novas concepções de ensino e aprendizagem da BNCC. Para atingir esse objetivo, fundamentado nos pressupostos teóricos e metodológicos do ensino híbrido e na reflexão do documento da BNCC, buscouse identificar se as atividades do livro possibilitam o uso de metodologias ativas e personalizadas de ensino, bem como conhecer se o livro atende à proposta da BNCC.

A partir da análise do livro, pôde-se perceber que, mesmo sendo um material aprovado pelo programa do PNLD, este carece de atividades que contribuam para o ensino ativo da língua inglesa, já que estas muitas vezes são descontextualizadas, parecem não atender às demandas dos estudantes, 
parecem não privilegiar o trabalho em grupo e o aprimoramento da autonomia dos estudantes, condições de fundamental importância para a prática de ensino e aprendizagem ativa, bases para o ensino híbrido.

As orientações da BNCC enfatizam que o ensino da língua inglesa deve levar em consideração as necessidades reais dos estudantes e que faça parte de suas realidades, para que estes possam atuar de forma crítica na sociedade a qual pertencem. Ainda para a BNCC, a aprendizagem do idioma deve ser orientada a contemplar todas as habilidades, tendo em vista que o referido documento considera 0 inglês como língua de expressão social e cultural para todos os seus falantes. Nesse sentido, o livro Time to Share parece atender de forma parcial a essas orientações, uma vez que as atividades são planejadas, em sua maioria, em língua portuguesa e estão centradas nas habilidades de leitura e escrita da língua.

O livro Manual do Professor Time to Share traz questões que podem possibilitar debates sobre temas relevantes, que podem fazer parte da realidade de muitos estudantes. A diversidade de nações e povos falantes da língua inglesa também é outra característica interessante no material, pois proporciona o contato com culturas diversas e a desmitificação do falante nativo, questão amplamente discutida pela BNCC no ensino da língua inglesa no Brasil.

A realização destas análises e reflexões, permitiram aprofundar o conhecimento sobre as perspectivas de ensino para a língua inglesa propostas pela BNCC e, também, a re(pensar) o papel do livro didático como recurso pedagógico, na construção ativa dos percursos formativos dos discentes. Uma sugestão para pesquisas futuras seria a proposição de material didático em consonância com 0 ensino híbrido e a BNCC, não desprezando a contribuição disponibilizada pelos materiais didáticos atuais.

\section{Referências}

BACICH, L; NETO, A. T; TREVISANI, F. M. (Orgs.). Ensino híbrido: personalização e tecnologia na educação. Porto Alegre: Penso, 2015.

BRASIL. Base Nacional Comum Curricular (BNCC). Educação é a base. Brasília, MEC. 2018. Guia de livros didáticos: PNLD 2020. Brasília: MEC, 2020.

CAMARGO, F; DAROS, T. A sala de aula inovadora: estratégias pedagógicas para fomentar o aprendizado ativo. Porto Alegre: Penso, 2018. 
CANAGARAJAH, A. S. From Babel to Pentecost: postmodern glottoscapes and the globalization of English. In ANGLADA, L; BARRIOS, M; WILLIAMS, J. (eds.) Towers to knowledge society: making EFL education relevant. 30th FAAPI conference, British Council, Argentina, p. 22-33, 2005.

MARCONI, M. d. A; LAKATOS, E. M. Fundamentos de metodologia científica. 5 ed. São Paulo: Editora Atlas, 2003.

LÉVY, P. Cibercultura. São Paulo: Editora 34, 1999.

LUDWIG, C. R; MACHADO, L. A. M. O "mundo plástico" dos materiais didáticos: uma análise do livro Interchange numa perspectiva intercultural. Revista Entreletras: Araguaína, v. 2, n. 2, p. 124-146, 2017. Disponível em:<https://sistemas.uft.edu.br/periodicos/index.php/entreletras/article/view/4128>. Acesso: 02 set. 2020.

MATTAR, J. Metodologias ativas: para a educação presencial, blended e a distância. Artesanato educacional: São Paulo, 2017.

MORAN, J. Educação híbrida: um conceito-chave para a educação, hoje. In BACICH, L; NETO, A. T; TREVISANI, F. M. (Orgs.). Ensino híbrido: personalização e tecnologia na educação. Porto Alegre: Penso, 2015.

POVIR. Educação sob medida. Disponível em: <https://personalizacao.porvir.org/>. Acesso em: 10 nov. 2019.

RAJAGOPALAN, K. Exposing young children to English as a foreign language: the emerging role of World English. Revista TLE: Campinas, v. 48, n. 2, p. 185-196, 2009.

SCHNEIDER, F. Otimização do espaço escolar por meio do modelo de ensino híbrido. In BACICH, L; NETO, A. T; TREVISANI, F. M.(Orgs.). Ensino híbrido: personalização e tecnologia na educação. Porto Alegre: Penso, 2015.

SILVESTRE, A. R. Time to Share, $6^{\circ}$ ano: ensino fundamental, anos finais. 2 ed. São Paulo: Editora Saraiva, 2020.

TÍLIO, R. A Base Nacional Comum Curricular e o contexto brasileiro. In: GERHARDT, A. F. L; AMORIM, M. A. de. (Orgs.) A BNCC e o ensino de línguas e literaturas. Editora Pontes, Campinas, 2019.

Data de submissão: 03/09/2021. Data de aprovação: 26/10/2021. 